\title{
ANOMALOUS PROPERTIES OF SMALL METAL PARTICLES AND OF THEIR ENSEMBLES
}

\author{
R.D.Fedorovich, A.G.Naumovets P.M.TomchuK \\ Institute of Physics \\ Ukrainian National Academy of Sciences \\ 46 Nauki Av., 252022 Kiev, Ukraine
}

Received September 12, 1995

\begin{abstract}
We present a review of experimental and theoretical studies of anomalous electronic properties observed to small metal particles. If the particle size is smaller than the electron mean free path in a volume, the electron-lattice energy exchange is strongly suppressed. This peculiarity, along with the possibility to feed high power densities into small particles, allows pronounced nonequilibrium heating of electrons and can cause specific electron and light emission from dispersed (island) metal films. The absorption of electromagnetic radiation by small metal particles is highly critical regarding their shape when the particle size is smaller than the wavelength and the radiation frequency is much lower than the plasma frequency.
\end{abstract}

\section{Introduction}

This paper deals with island metal films (IMF's) representing ensembles of metal particles deposited on dielectric substrates and coupled by the electron tunneling. In most cases IMF's are prepared by vacuum evaporation. The mean size and shape of the islands as well as mean distance between them can be varied widely by choosing deposition regimes (figure 1).

Each time the size of a metal particle becomes equal to a characteristic length, such as the de Broglie wave length, electron mean free path, skin depth, incident electromagnetic wavelength etc., so the properties of a particle exhibit some physical peculiarities. This, together with the effects of electron tunneling, gives rise to anomalous properties of IMF's due to which the latter are different from continuous films and bulk metals. The well known examples of such anomalies are negative thermal coefficient of resistance, non-ohmic conductivity, peculiarities of optical absorption (its high sensitivity to an island shape) etc. [1].

Here we will concentrate on phenomena which occur when considerable power densities are pumped into IMF's either by laser irradiation or by current flow [2]. Whatever the way of power pumping, an emission of electrons and photons is observed. Under some particular conditions a voltagecontrolled negative resistance (VCNR) [3] appears also. The nonstandard nature of these phenomena can be exemplified by the following observation. The irradiation of an IMF with a pulsed IR laser $(\lambda=10.6 \mathrm{~mm})$ causes an unusual photoeffect which holds despite the energy of incident quanta 
is $\approx 40$ times as low than the metal work function and the multiquantum effects are negligible under laser intensities used. Moreover, some emitted electrons have energies which are much higher than those of incident photons.

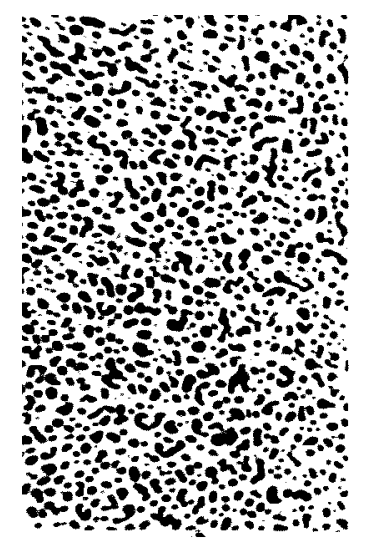

a)

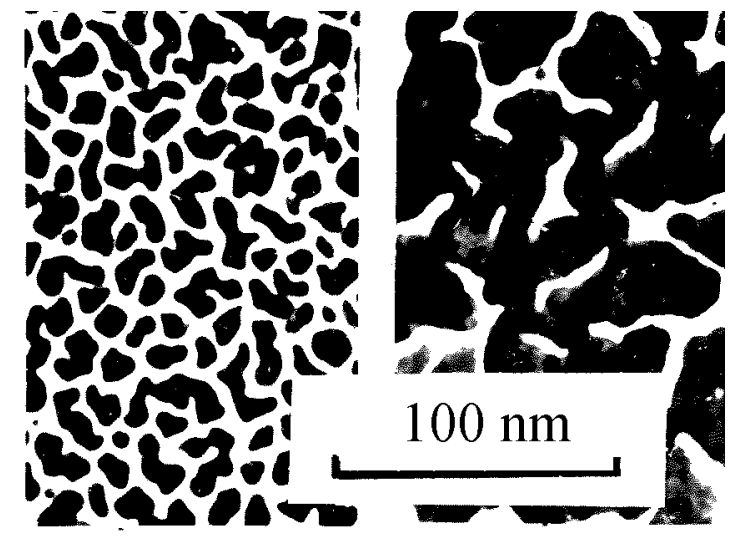

b)

c)

Figure 1. Electron microghaphs of $\mathbf{A u}$ island film on $\mathbf{S i O}_{x}$ at mass thickness of $3.5 \mathrm{~nm}$ (a), $5 \mathrm{~nm}$ (b) and $9 \mathrm{~nm}$ (c).

\section{Theory}

The essence of the theory elaborated by one of us (P.T.) and aimed at explanation of the specific electron and photon emission from IMF's is the substantiation of the possibility of strong nonequilibrium heating of the electron gas in small metal particles [4].

In the framework of this theory the photoeffect from IMF's is interpreted as a thermionic emission of hot electrons (their temperature can amount to a few thousand Kelvins while the crystal lattice remains cold) and the photon emission is ascribed to bremsstrahlung and inverse photoeffect.

Until recently, the hot electrons were shown to exist under steady-state conditions only in gaseous and semiconductor plasmas whereas in metals they could be obtained only for very short periods of time $\left(t<10^{-10} \mathrm{~s}\right)$ [4]. The question arises why the hot electrons can be generated in IMF's in a steady state, i.e. as long as a power is fed into an IMF. To answer this question let us consider a system of balance equations which link the electron and lattice temperatures, $T_{e}$ and $T$, in a metal particle:

$$
\begin{aligned}
& \frac{\partial}{\partial t}\left(C_{e} T_{e}\right)=\operatorname{div}\left(K_{e} \nabla T_{e}\right)-\alpha\left(T_{e}-T\right)+Q, \\
& \frac{\partial}{\partial t}(C T)=\operatorname{div}(K \nabla T)+\alpha\left(T_{e}-T\right) .
\end{aligned}
$$

Here $C_{e}$ and $C$ are the electron and lattice heat capacities, $K_{e}$ and $K$ the corresponding heat conductivities and $Q$ a power density absorbed by a metal island. The coefficient $\alpha$ determines the electron-lattice energy exchange and therefore the term $\alpha\left(T_{e}-T\right)$ describes the energy transfer from electrons to the lattice. Equations (1) should by supplemented by 
boundary conditions characterizing the heat transfer from an island to a dielectric substrate.

Let us now compare the electron-lattice energy exchange in a bulk metal and a small metal particle. Since heat capacity of the electron gas is much smaller than that of the crystal lattice, electrons are quickly heated up as the power is fed and, after a time of $\tau_{e} \sim \alpha / C_{e}$ (equal to $\sim 10^{-12} s$ for a bulk metal), their temperature $T_{e}$ attains a steady-state value. From this time one has a balance

$$
\alpha\left(T_{e}-T\right) \approx Q
$$

i.e. the whole power, being pumped into the electron system is drained to the lattice. During the times $t<\tau_{e}$ the lattice temperature $T$ does not keep pace with $T_{e}$, but after a time of $t \sim \alpha / C \sim 10^{-10} s$ the temperatures $T_{e}$ and $T$ must equalize. For this reason the hot electrons in bulk metals can be obtained only in a pulsed regime, e.g. when short $\left(t<10^{-10} s\right)$ but intense laser impulses are irradiating a metal surface.

On the contrary to this situation, there are three important distinctions in IMF's:

(i) for a metal particles whose dimension is smaller that the electron mean free path, the coefficient $\alpha$ is reduced by an order of magnitude in comparison with the bulk metal;

(ii) considerable power densities can be pumped into small metal particles;

(iii) an island which has a good heat contact with the dielectric substrate is able to pass intense energy fluxes through itself without selfdestruction, and its thermal stability increases if the size is reduced.

Let us discuss these features in more detail. It is known that the major channel of energy losses of electrons is generation of acoustic waves by the Cherenkov mechanism [5,6]. An electron whose velocity is much higher than the sound velocity generates an acoustic wave which is described by the equation

$$
\frac{\partial^{2} \vec{U}}{\partial t^{2}}-s^{2} \Delta \vec{U}=-\frac{W}{\rho} \nabla \delta(\vec{r}-\vec{v} t) \equiv \vec{f}(t),
$$

where $\vec{U}$ is the longitudinal component of the displacement vector, $\rho$ - the density and $W$ - an interaction coefficient. The energy lost by an electron in a time unit due to the acoustic wave generation is equal

$$
\frac{d E}{d t}=W \int \frac{\partial \vec{U}}{\partial t} \nabla \delta(\vec{r}-\vec{v} t) d^{3} r
$$

Eqn. (3) can be easily solved in the Fourier representation:

$$
\vec{U}(\omega, \vec{k})=\frac{1}{(2 \pi)^{3}} \cdot \frac{W}{\rho} \cdot \frac{\mathrm{i} \vec{k} \delta(\omega-\vec{k} \vec{v})}{\omega^{2}-k^{2} s^{2}} .
$$

It is seen that a resonant excitation of acoustic waves is possible at the frequency $\omega=k s$ (the Cherenkov mechanism). However, this excitation cannot occur if the driving force $f(t)$ in Eqn. (3) has a zero Fourier component at the resonance frequency. Just such a situation exists in a metal particle when its size $L$ is smaller than the electron mean free path. Then the electron trajectory, instead of being a straight line $\vec{r}(t)=\vec{v} t$, becomes 
oscillating with the frequency $\nu=v / L$, which is due to successive reflections of the electron from the particle boundaries. In this case the force $f(t)$ should have harmonics only at frequencies which are multiples of $\nu$. The resonant excitation of acoustic vibration will be impossible if the frequency $\nu_{F}=v_{F} / L\left(v_{F}\right.$ being the Fermi velocity) is higher than the Debye frequency $\nu_{D}$, i.e. the highest frequency of the lattice vibrations. It is readily seen that the condition $\nu_{F}>\nu_{D}$ is fulfilled for small islands $(L<100 \AA)$. In such islands the major mechanism of energy losses, operating in bulk samples and large islands, vanishes and the surface scattering of electrons becomes dominating. A theory of surface energy losses [7] predicts the corresponding $\alpha$ value to be by a factor of $\sim 10^{2}$ lower then its volume value inherent to bulk metals. This estimation was supported experimentally [8].

Consider now the factors which allow pumping high power densities into small metal particles in IMF's, i.e. providing high Q's in Eqn. (2). In the case of conduction current pumping, one observes (after a forming procedure) the appearance of conductive channels with a very high current density which results in the release of a high power in some islands. The high $Q$ values under $\mathbf{C O}_{2}$ laser irradiation $(\lambda=10.6 \mu \mathrm{m})$ are due to enhanced IR optical absorption by small metal particles [9]. It is important to note that the power absorbed by an island depends very critically on its shape so the high Q's are possible only for some islands. As follows from Eqn. (2), small values of $\alpha$ and high values of $Q$ entail the high electron temperature $T_{e}$.

The high thermal stability of small islands is caused by the circumstance that the power is received by their electrons which cannot penetrate the nonconducting substrate, while the heat from the island crystal lattice is effectively drained off to the substrate lattice. This differs radically from the situation in bulk metals where the phonon system accepting the thermal load has the same volume as the electron system.

The physical reasons presented above enable the electron gas in small metal particles to be heated to thousands of Kelvins while the crystal lattice remains essentially cold. In other words a strongly nonequilibrium system can be realized in a quasi-steady state, which brings about a variety of specific effects in IMF's.

\section{Experimental results}

Below there are some examples of experimental data on emission phenomena in IMF's and their application potentialities.

\subsection{Electron and photon emission from IMF's under IR laser irradiation}

The IR laser excitation is the most convenient method for observation of electron emission, since no structure-forming procedure is needed here unlike to the current excitation. IMF's are deposited on substrates transparent to the exciting laser radiation. In most experiments we used a pulsed $\mathbf{C O}_{2}$ laser $(\lambda=10.6 \mu \mathrm{m}$, TEA mode, $\tau=0.2 \div 1.0 \mu \mathrm{s}, f=1 \div 30 \mathrm{~Hz})$ and island films deposited in vacuum onto silicon plates. The measurements were carried out either in situ in the same vacuum tube or in another vacuum tube after transfering the prepared sample through air. The laser beam was passed through a silicon window.

The emission current distribution over the IMF surface is visualized on a cathodoluminescent screen placed parallel to the sample. figure 2 shows 
an example of obtained patterns imaging the intensity distribution in an IR laser beam.

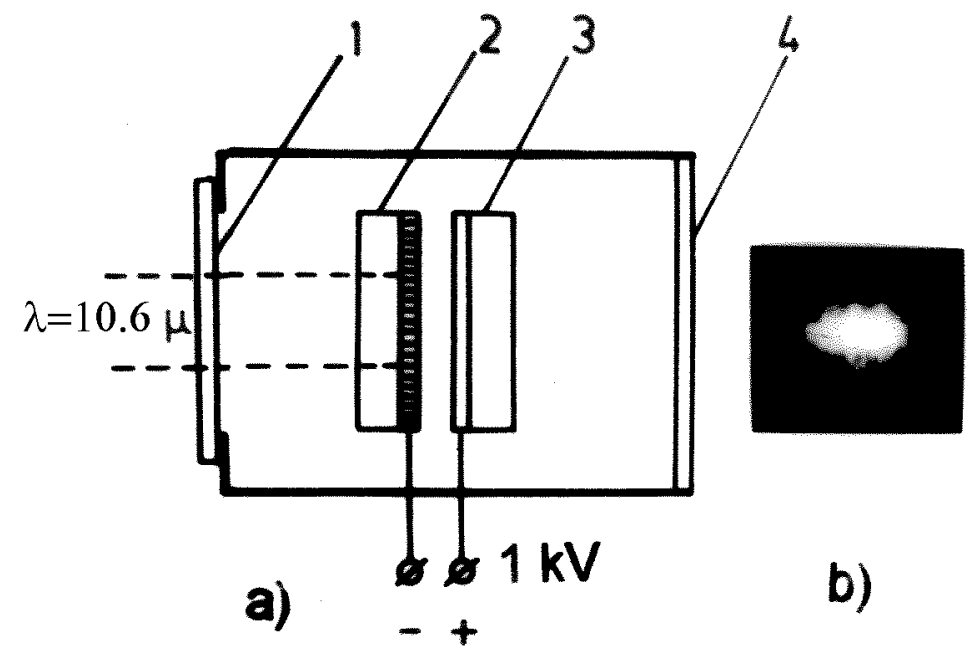

Figure 2. (a) Scheme of an electron-optical transformer using an island film photocathode. 1 is a $\mathbf{S i}$ entrance window, 2 the cathode, 3 luminescent screen and 4 glass window. (b) Intensity distribution in a $\mathbf{C O}_{2}$ laser beam $(\lambda=$ $10.6 \mu \mathrm{m})$, visualized with a photocathode based on a nanocomposite material porous Si-Ba-BaO.

The in situ investigations of electron emission and structure of IMF's have shown that a measurable emission current from gold island films appears at a laser beam power density of $\sim 10^{4} \mathrm{Wt} / \mathrm{cm}^{2}$ whereas for bulk Au this value must be above $\sim 10^{7} \mathrm{Wt} / \mathrm{cm}^{2}[10]$. No significant change in the shape of $\mathrm{Au}$ islands is apparent below $2 \times 10^{5} \mathrm{Wt} / \mathrm{cm}^{2}$. Above this value one firstly observes the evaporation of comparatively large $\mathrm{Au}$ islands $\left(\sim 10^{2} \mathrm{~nm}\right)$ while small islands stand up to much higher powers. Stability of IMF's increases when they are prepared from refractory materials, e.g. from graphite.

The light emission from IMF's sets in simultaneously with the electron emission. The time lag in electron and light emission is below $\sim 2 \times 10^{8} \mathrm{~s}$ so the shape of their pulses reproduces almost exactly the shape of exciting laser pulses. The time lag becomes pronounced only at high power densities when also a rather fast evaporation of islands occurs. In this case the electron emission is most likely caused by usual thermionic mechanism.

Consider now some further data on the electron emission at low and moderate excitation powers. Measurements of energy spectra of electrons emitted from $\mathbf{A u}$ island films detected that rather a let of electrons have energies of about a few electron-Volts [11]. The emission current $\left(I_{e}\right)$ as a function of the power of the exciting IR laser beam $(P)$ is linear in coordinates $\log I_{e}$ versus $1 / \sqrt{P}$. This agrees with the model which views the electron emission from IMF's as a Richardson emission of nonequilibrium (hot) electrons [4]. As mentioned above the absorbed power, and therefore the emission current, should strongly depend on size and shape of small particles. This is mirrored in some nonuniformity of the brightness of emission patterns researched. 
The electron and light emission intensity is also sensitive to the nature of adsorbed molecules which may be present at the surface of islands. For example the light intensity can by enhanced owing to excitation of the molecules by hot electrons [12]. The highest mean density of a stable electron emission current obtained from Au IMF's was about $10^{-2} \mathrm{~mA} / \mathrm{cm}^{2}$. For graphite films this value amounted to $\sim 1 \mathrm{~A} / \mathrm{cm}^{2}$ at the laser beam power of $10^{5} \mathrm{Wt} / \mathrm{cm}^{2}$. The highest emissivity has been found for composite Si-Ba-BaO cathodes fabricated on the basis of porous silicon substrates.

\subsection{Electron and photon emission from IMF's induced by pass- ing a current}

In order to obtain electron and photon emission from an IMF using the conduction current excitation, it is first necessary to subject the film to a "forming" procedure [13]. The forming occurs when an increased voltage is applied to as-deposited (high resistance) film. The arising electromigration leads to appearance of low-resistance current channels [14]. The potential along each channel is usually strongly nonuniform, and a considerable power is released within a submicron area. The electron and light emission originates just from such areas (sites), which coincide for both kinds of emission. The light emission from an IMF is usually seen as a chain of variously coloured spots, the chain being oriented parallel to the contacts [15]. Later on we used substrates with parallel grooves on their surface (diffraction gratings). Films prepared on such a substrate consist of parallel island chains. Forming is not needed here, since the current channels exist from the beginning. The emission current (at the level of $\sim 10^{-12} \mathrm{~A}$ ) appears typically at voltages of $10 \div 15 \mathrm{~V}$ where the conduction currentvoltage characteristic is non-ohmic (figure 3 ). It has been found that the

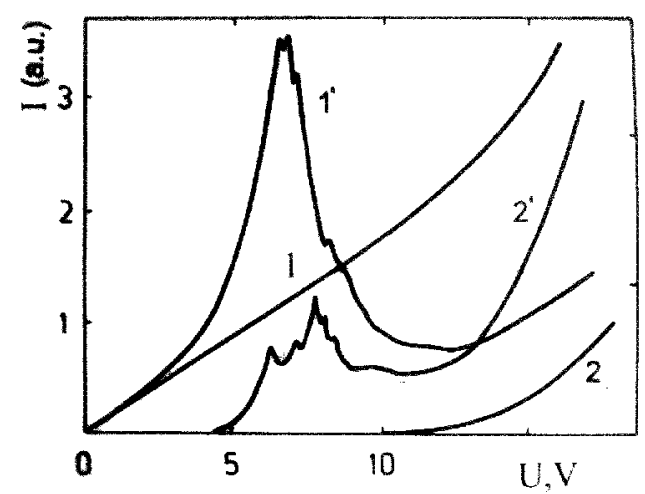

Figure 3. Current-voltage curves of conduction current (1) and electron emission (2) for an Au island film. (1') and $\left(2^{\prime}\right)$ the same characteristics after deposition of organic molecules.

dependence $\log I_{e}=f(1 / \sqrt{I V})$, with $I$ being the conduction current and $V$ the applied voltage, is mostly linear. However, some deviation to higher emission currents is observed at high $V$ 's. This behaviour may be attributed to a certain fall of the inter-island potential barriers by the electric field. In other words a regime of the nonequilibrium thermofield electron emission is suggested [16]. 
The energy of emitted electrons can attain $1.5 \div 2.0 \mathrm{eV}[17]$. The spectra of the light emission depict usually a few rather broad bands in the visible range $[20]$.

The conduction current as well as the electron emission current and the light emission intensity increase when an adsorbate is evaporated on an IMF and the work function is they lowered. However, the general shape of the conduction current-voltage curve remains unchanged in this case. Quite a different behaviours is observed upon adsorption of hydrated hydrocarbon molecules (see below).

A cold microcathode has been developed using gold IMF's activated by adsorbed $\mathbf{B a O}$ molecules [18]. Its parameters are as follows: the width of the gap between the contacts is $10 \mu \mathrm{m}$; the cathode area $(3 \div 4) 10^{-4} \mathrm{~cm}^{2}$; the emission current is $100 \div 150 \mu \mathrm{A}$ at the voltage of $20 \div 30 \mathrm{~V}$; emission current to conduction current ratio is $5 \div 10 \%$ at the efficiency of $1 \mathrm{~mA} / \mathrm{Wt}$; the local current density within emission sites is 0.5 to $1 \mathrm{~A} / \mathrm{cm}^{2}$; the response time is $<0.1 \mu \mathrm{s}$ and the longevity $>4000 \mathrm{~h}$. Such cathodes can easily be fabricated in various geometrical configurations, e.g. for using them in vacuum 7-segment digit indicators. Employing a special form of contacts one can also make large-area $\left(\sim 1 \mathrm{~cm}^{2}\right)$ IMF cathodes (figure 4$)$.

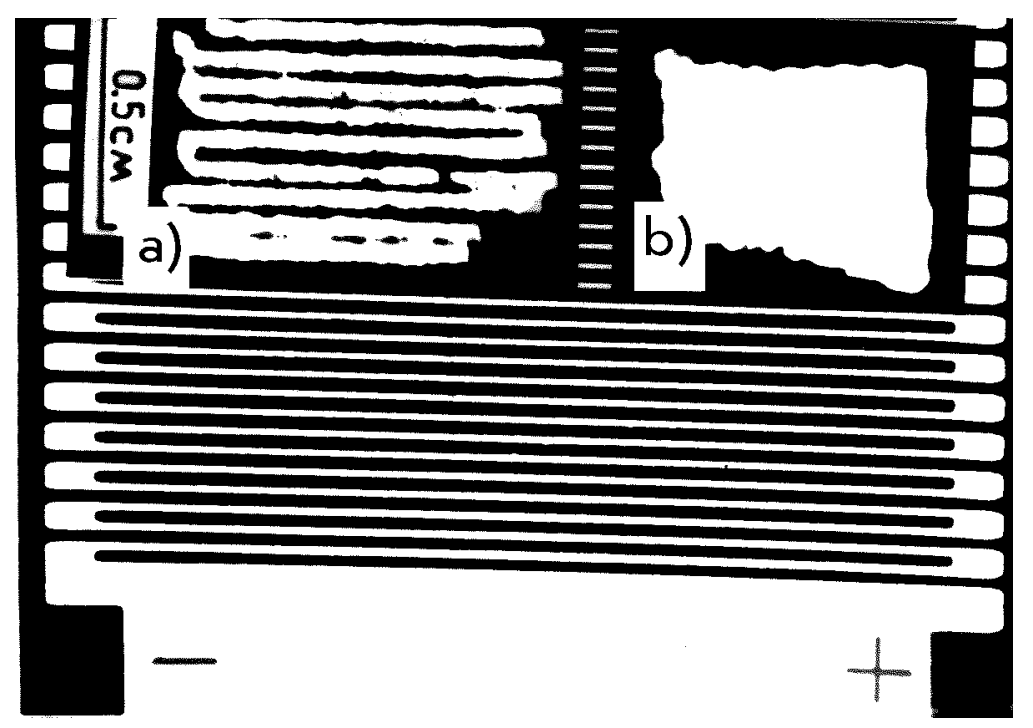

Figure 4. Enlarged image of a cold island-film cathode with comb-like contacts (seen as dark lines). The islands (not seen) are deposited in the gaps (white areas). Insets: patterns of electron emission from the cathodes with gaps $0.7 \mathrm{~mm}$ (a) and $40 \mu \mathrm{m}$ (b).

Adsorption of some organic molecules on IMF's with formed current channels results in appearance of voltage-controlled negative resistance (VCNR) [3,19]. Simultaneously the voltage dependences of the electron and light emission are also changed [20]. These findings are ascribed to the influence of organic molecules on the conductivity of interisland gaps within emission sites. The electromigration of the polar molecules to these sites where the electric field is the highest can enhance the conductivity and impart qualitatively new features to the film. As the voltage applied to the film is increased, the molecules can be evaporated by resistive heating 
and the conductivity regains its initial value. The process can be reversibly repeated many times. Some authors attribute the effect of organic molecules to the formation of carbon "bridges" within the emission sites [21], but this hypothesis seems to be improbable because it is hard to remove the carbon by heating.

Some IMF's exhibit a property of the field memory by conserving their high-resistance state at the zero voltage for a long time. The ratio of the high resistance to the low resistance equals usually 10-50, but for the IMS's consisting of parallel chains of islands this ratio is larger by orders of magnitude [22].

\section{Conclusion}

The results presented in this work demonstrate an interesting size effect in small metal particles: the suppression of electron-lattice energy transfer, which makes possible strong nonequilibrium heating of electrons. This phenomenon entails a number of other effects such as the specific electron and light emission under pumping a power into ensembles of small particles, e.g. island metal films. Taking account of the generation of hot electrons in small particles should be performed when developing and exploiting nanoelectron devices, various nanosized systems including porous materials, supported dispersed catalysts etc.

\section{Acknowledgements}

We gratefully acknowledge the financial support by the Foundation ISFUkraine, Grants K 57100 (R.D.F.) and K6D100 (P.M.T) and by the INTAS Association, Project 93-0964 (A.G.N.). Thanks are due to Mr. M.Paliy for his help in preparation of the typescript.

\section{References}

[1] Stefanou N., Modinos A. Optical properties of thin discontinuous metal films. // J. Phys. Condens. Matter, 1991, vol. 3, p. 8149-8157.

[2] Fedorovich R.D., Naumovets A.G., Tomchuk P.M. Electronic properties of island thin films caused by surface scattering of electrons. // Progr. Surface Sci., 1993, vol. 42, No 1, p. 189-200.

[3] Pagnia H., Sotnik N. Bistable switching in electroformed metal-insulatormetal devices. // Phys. Stat. Solidi (a), 1988, vol. 108, No 1, p. 11-65.

[4] Belotskii E.D., Tomchuk P.M. Electron-phonon interaction and hot electrons in small metal islands. // Surface Sci., 1990, vol. 239, No 1, p. 143-155.

[5] Buckingham M.J. The interaction of electrons with lattice vibrations: radiation by a fast electron. // Proc. Phys. Soc., 1963, B6, p. 601.

[6] Kaganov M.I. Lifshits I.M., Tanatarov L.V. Relaxation between electrons and lattice. // Sov. Phys. JETP, 1957, vol. 4, p. 173-178.

[7] Belotskii E.D., Lukianets S.P., Tomchuk P.M. A theory of hot electrons in island metal films. // Sov. Phys. JETP, 1992, vol. 74, No 1, p. 88-94.

[8] Gorban S.A., Nepijko S.A., Tomchuk P.M. Electron-phonon interaction in small metal islands deposited on insulating substrate. // Int. J. Electronics, 1991, vol. 70, No 3, p. 485-490.

[9] Tomchuk P.M. Light absorption by island films in the infrared range. // Surface Sci., 1995, vol. 330(3), p. 350-366. 
[10] Schoenlein R.W., Lin W.Z., Fujimoto I.G. Femtosecond studies of nonequilibrium electronic processes in metals. // Phys. Rev. Lett., 1987, vol. 58, No 16, p. $1680-1683$.

[11] Nepijko S.A., Gorban' S.A., Viduta L.V., Fedorovich R.D. Energy distribution of IR-induced electron emission from metal island films. // Int. J. Electronics, 1992, vol. 73, No 5, p. 1011-1015.

[12] Dan'ko D.B., Fedorovich R.D., Gaidar A.V., Poroshin V.N. Electron and photon emission from discontinuous carbon films. // Int. J. Electronics, 1992, vol. 73, No 5, p. 1005-1008.

[13] Blessing R., Pagnia H., Sotnik N. The electroforming process in MIM diodes. // Thin Solid Films, 1981, vol. 85, No 2, p. 119-128.

[14] Alekseenko B.V., Fedorovich R.D. Influence of adsorption on current-voltage characteristics of discontinuous metal films. // Thin Solid Films, 1982, vol. 92, No 3, p. 253-258.

[15] Borzjak P.G., Sarbej O.G., Fedorovich R.D. Neue Erscheinungen in sehr dunnen Metallschichten. // Phys. Stat. Sol., 1965, vol. 8, No 1, p. 55-58.

[16] Fedorovich R.D., Naumovets A.G., Ostranitsa A.P., Tomchuk P.M. Electron emission from regular chain-like island structures. // Int. J. Electronics, 1990, vol. 69 , No 1, p. 179-183.

[17] Araki H., Hanawa T. Electron emission from electroformed carbon films. // Vacuum, 1988, vol. 38, No 1, p. 31-35.

[18] Sukharier A.S., Zagrebneva S.V., Suchilin V.M., Trusakov V.M. Investigation of the emission properties of discontinuous gold films activated by $\mathrm{BaO}$. // Elektr. Tekhn., ser. 5, 1969, No 2, p. 10-18 (in Russian).

[19] Alekseenko B.V., Fedorovich R.D., Tomchuk P.M. The effect of adsorption in development of the VCNR in island metals film. // Materials Science, 1987, vol. 13, No 3-4, p. 161-166.

[20] Fedorovich R.D., Kiyayev O.E., Naumovets A.G., Pilipchak K.N., Tomchuk P.M. Electronic size effects in small metal particles and emission phenomena in island metal films. // Phys. Low.-Dim. Struct., 1994, vol. 1, p. 83-92.

[21] Pagnia H., Schnellbacher J., Sotnik N. Regeneration model for conducting filaments in MIM diodes. // Phys. Stat. Sol. (a),1985, vol. 87, p. 709-717.

[22] Viduta L.V., Kiyayev O.E., Naumovets A.G., Ostranitsa A.P., Fedorovich R.D. Electron emission from gold and graphite films of a special structure under conduction current and IR laser excitation. // Sov. J. Commun. Technol. Electron., 1992, vol. 37, No 1, p. 98-104.

\title{
АНОМАЛЬНІ ВЛАСТИВОСТІ МАЛИХ МЕТАЛІЧНИХ ЧАСТИНОК TA İ АНСАМБЛIB
}

\author{
Р.Д.Федорович, А.Г.Наумовець, П.М.Томчук
}

\begin{abstract}
Подається огляд експериментальних і теоретичних досліджень аномальних електронних властивостей малих металічних частинок. Електрон-гратковий обмін енергією сильно подавляється, якщо розмір частинки менший від довжини вільного пробігу електрона в об'ємі. Ця особливість разом з можливістю
\end{abstract}


накачки в малі частинки енергії високої густини робить можливим значне нерівноважне нагрівання електронів і може спричиняти емісію електронів з (острівних) металевих плівок. Поглинання електромагнітного випромінювання малими металічними частинками є критичним для їх форми, коли розмір частинки менший від довжини хвилі, а частота випромінювання значно менша від частоти плазми. 